\title{
Giant left main coronary artery aneurysm
}

\author{
Mehmet Ozkan $M D^{1}$, Mustafa Yildiz $\mathrm{MD}^{2}$, Ibrahim Koker $\mathrm{MD}^{3}$
}

\begin{abstract}
A 60-year-old man without known coronary artery disease presented with chest pain. A coronary angiogram revealed proximal stenosis of the left anterior descending artery and the circumflex artery, as well as an aneurysm of the left main coronary artery, which measured $24 \mathrm{~mm} \times 16 \mathrm{~mm}$ (Figures 1 and 2). The right coronary artery was normal. The patient underwent surgery; the left anterior descending artery was grafted with the left internal thoracic artery, and the circumflex artery was grafted with a saphenous vein.

Aneurysms of the left main coronary artery are extremely rare (1). Atherosclerotic disease is often the primary etiology
\end{abstract}

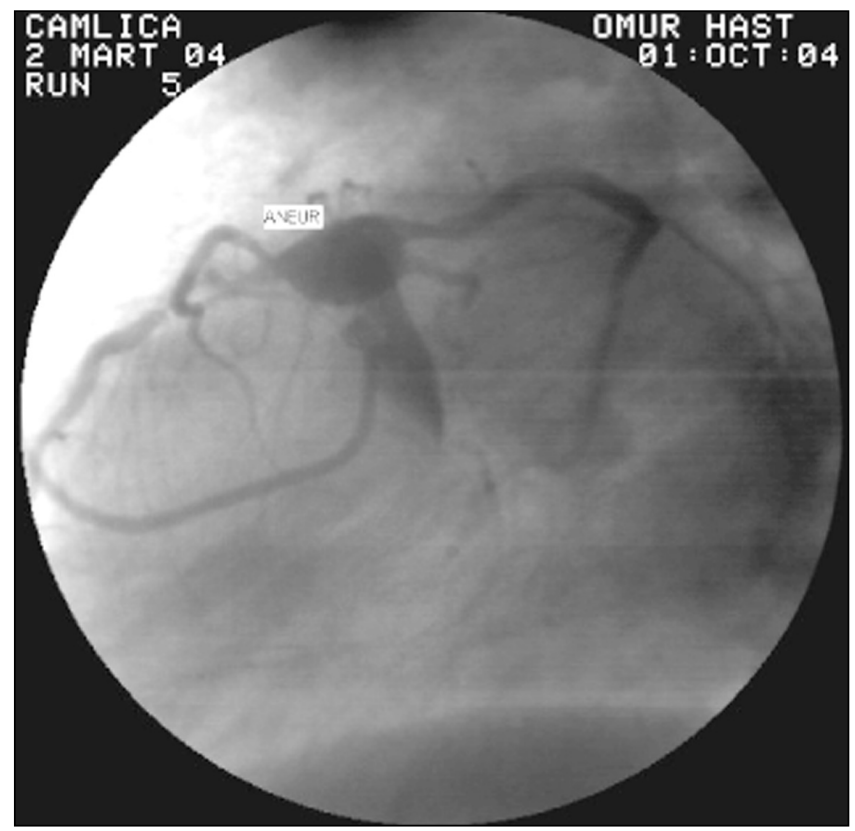

Figure 1) An aneurysm (ANEUR) of the left main coronary artery in the adult population. The main complication is myocardial infarction, but aneurysm rupture can sometimes occur. Because of the rarity of left main coronary artery aneurysms, there is no standardized treatment (2).

\section{REFERENCES}

1. Topaz O, DiSciascio G, Cowley MJ, et al. Angiographic features of left main coronary artery aneurysms. Am J Cardiol 1991;67:1139-42.

2. Unic D, Mihaljevic T, Leacche M, Gasparovic H, Albert MA, Byrne JG. Surgical treatment of a large left-main coronary artery aneurysm.

Thorac Cardiovasc Surg 2004;52:230-1.

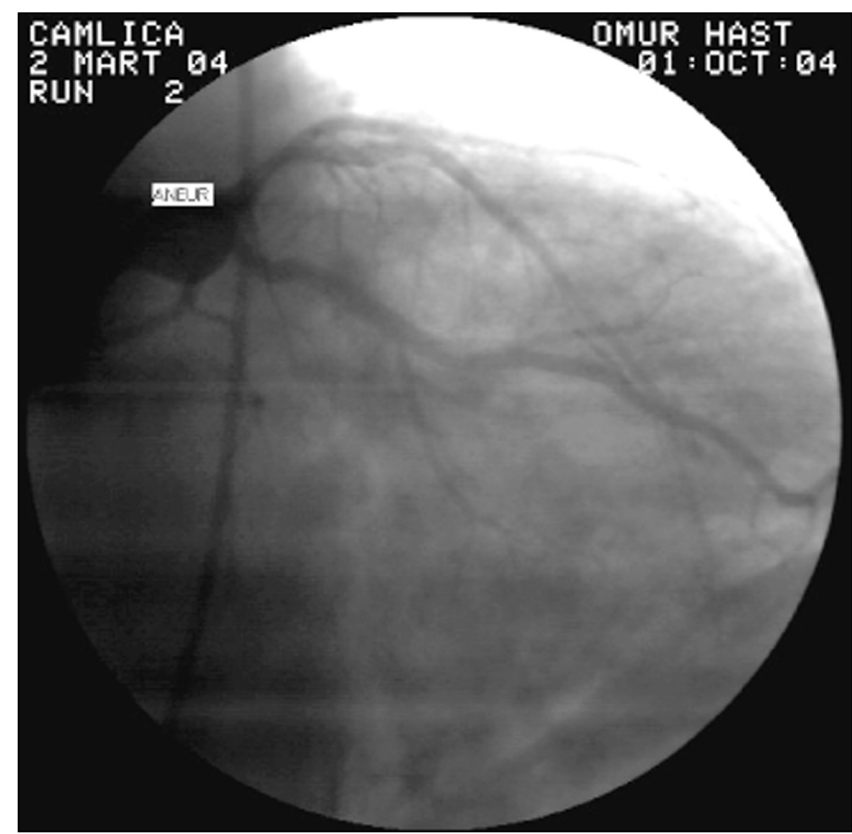

Figure 2) An aneurysm (ANEUR) of the left main coronary artery

${ }^{1}$ Department of Cardiology, Çamlica Ömür Hospital, Istanbul; ${ }^{2}$ Sakarya University School of Health, Sakarya; ${ }^{3}$ Department of Internal Medicine, Isviçre Hospital, Istanbul, Turkey

Correspondence: Dr Mustafa Yildiz, Bayar Cad, Gülbahar Sok, Emniyet Sitesi No: 11 A Blok A Kapısı Daire 6, Kozyataği, Istanbul, Turkey. Telephone 90-532-371-1701,fax 90-264-346-04-7172, e-mail mustafayilldiz@yahoo.com

Received for publication March 28, 2006. Accepted April 2, 2006 